\title{
Emergency medical service personnel need to improve knowledge and attitude regarding prehospital sepsis care
}

\author{
Joongmin Park, Sung Yeon Hwang, Tae Gun Shin, Ik Joon Jo, Hee Yoon, \\ Tae Rim Lee, Won Chul Cha, Min Seob Sim
}

Department of Emergency Medicine, Samsung Medical Center, Sungkyunkwan University School of Medicine, Seoul, Korea

Objective We aimed to evaluate the knowledge and attitudes of emergency medical service (EMS) personnel pertaining to sepsis. We also compared EMS personnel's knowledge of sepsis and their intention to engage in prehospital sepsis management.

Methods The survey was conducted during education conferences for EMS personnel in December 2013 and January 2015 in Seoul, Korea. The questionnaire composed of 10 questions relevant to sepsis, was distributed on-scene, and was retrieved by investigators after the conference. We classified subjects into active and passive groups based on intent to participate in prehospital sepsis care.

Results A total of 271 questionnaires were distributed; 255 EMS personnel (94\%) completed the survey, 126 (49\%) of whom were first-degree emergency medical technicians (EMTs). Less than $75 \%$ of subjects provided clinically relevant responses to questions about the definitions of sepsis, tachycardia, tachypnea, hypotension, hypothermia, fluid resuscitation, and vasopressor. Only $15 \%$ of participants had suspected that a patient had sepsis, and $9 \%$ reported that they could identify patients with sepsis during transportation. Overall, first-degree EMTs showed higher levels of knowledge and a positive attitude to sepsis compared with non-first-degree EMTs. Sixty percent of the participants reported that they were actively involved in prehospital sepsis care. The active group showed significantly higher levels of knowledge and more positive responses to the clinical impact of prehospital sepsis care.

Conclusion Our study showed that is a substantial portion of EMS personnel lacks appropriate level of knowledge on sepsis care. We also found that the intention to engage in sepsis management was associated with appropriate knowledge of sepsis.

Keywords Sepsis; Emergency medical services; Knowledge; Attitude

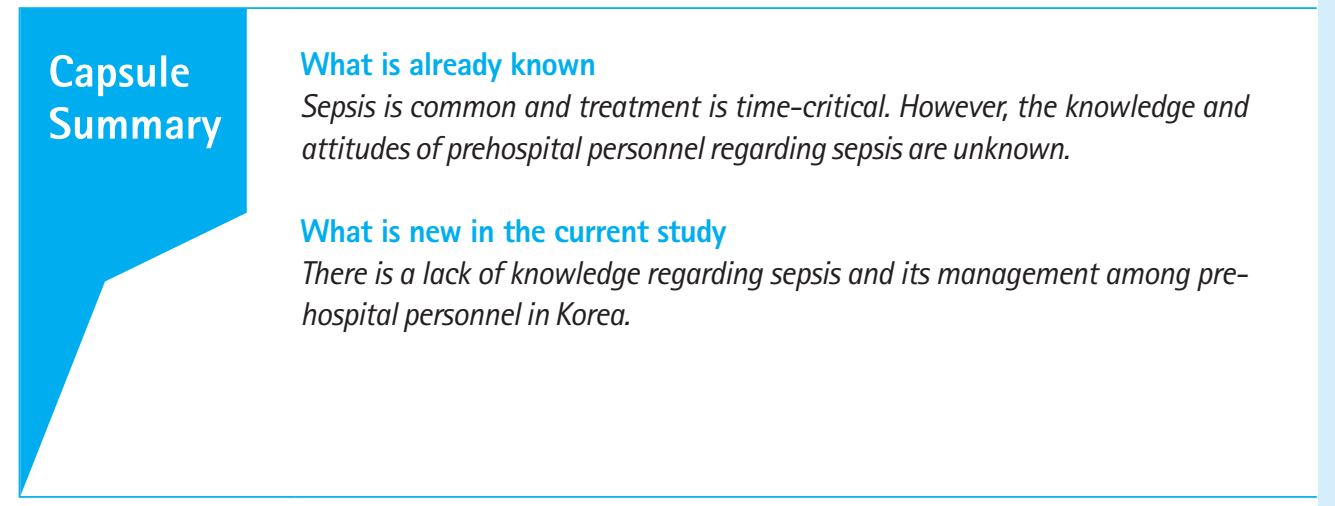

Received: 27 December 2016

Revised: 20 January 2017

Accepted: 25 January 2017

Correspondence to: Sung Yeon Hwang Department of Emergency Medicine, Samsung Medical Center, Sungkyunkwan University School of Medicine, 81 Irwon-ro, Gangnam-gu, Seoul 06351, Korea

E-mail: gerup@hanmail.net

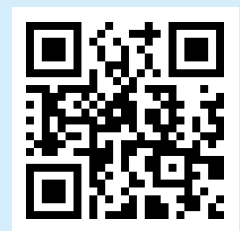

How to cite this article: Park J, Hwang SY, Shin TG, Jo IJ, Yoon H, Lee TR, Cha WC, Sim MS. Emergency medical service personnel need to improve knowledge and attitude regarding prehospital sepsis care. Clin Exp Emerg Med 2017;4(1):48-55.

This is an Open Access article distributed under the terms of the Creative Commons Attribution Non-Commercial License (http:// creativecommons.org/licenses/by-nc/4.0/). 


\section{INTRODUCTION}

Sepsis is a leading cause of death worldwide, and the incidence of sepsis has increased over the past decades due, in part, to increasing age and chronic illness. ${ }^{12}$ Like acute myocardial infarction and cardiac arrest, sepsis is time-sensitive. It is clear that early recognition and timely management of sepsis improve patient outcome. ${ }^{3-6}$

Approximately 30\% to 50\% of patients with sepsis are transported to the emergency department (ED) by emergency medical service (EMS). ${ }^{7-10}$ It implies that the prognosis of these patients would be influenced by prehospital care performed by EMS personnel. ${ }^{11}$ As EMS personnel might be the first health care providers for patients with sepsis, they are very important in initiating the cascade of sepsis care before hospital arrival. To provide optimal sepsis care in a prehospital setting, EMS personnel should be familiar with the disease and proactively involved in sepsis care. However, understanding of sepsis among EMS personnel might be insufficient, which can negatively impact their attitude and performance. ${ }^{12}$

We conducted this survey to evaluate the knowledge and attitudes of EMS personnel regarding sepsis care and to compare their understanding about sepsis based on willingness to be involved in prehospital sepsis care.

\section{METHODS}

\section{Study design and data collection}

The survey was conducted during education conferences for EMS personnel in December 2013 and January 2015 in Seoul, South Korea. Our subjects were EMS personnel who work at the fire stations in a metropolitan city. ${ }^{13}$

The questionnaire was composed of 10 sepsis-related questions and was developed based on previous survey studies (Appendix 1)..$^{14}$ The survey was designed to assess basic knowledge of the diagnosis and treatment of sepsis, as well as the attitude toward managing sepsis patients in a prehospital setting. A questionnaire was distributed to all participants at the beginning of the conference. They were asked to complete the questionnaire during the conference, and it was later retrieved by investigators.

The institutional review board of our institute approved this study, and written informed consent was obtained from each participant before performing the survey. No incentives were offered for participation in the survey.

\section{Study population}

EMS personnel in South Korea are categorized into first-degree emergency medical technicians (EMTs), second-degree EMTs, and drivers. Based on their medical roles and certification, these are analogous to EMT-intermediate, EMT-basic, and first responder, respectively, in the US EMS system. First-degree EMT is the highest level of EMT certification, and these subjects undergo at least three years of training at a vocational college. They are certified to perform advanced cardiopulmonary life support including endotracheal intubation, intravenous access, and administration of limited rescue drugs under the on-line medical directions by physicians. First-degree EMTs also perform all of the same functions as second-degree EMTs and drivers. Second-degree EMTs and drivers are usually trained at fire departments or other certified facilities. Their performance is limited to basic cardiopulmonary life support, wound management, and patient assessment. Most ambulances are staffed by one or two EMTs (first-degree EMT and/or second-degree EMT) and a driver.

\section{Data analysis}

We classified participants into first-degree EMT group and nonfirst-degree EMT group (second-degree EMT and driver) for data analysis. We also classified EMS personnel into active and passive groups according to their participatory intentions in prehospital sepsis care. The active group was defined as EMS personnel who answered 'yes' to question 10 (are you willing to be actively engaged in the management of sepsis in the prehospital setting?). The passive group was composed of subjects who answered 'no or not sure' to this same question. Knowledge and perception were considered insufficient when subjects responded to $<75 \%$ of the questions appropriately.

Data are presented as mean with standard deviation for numerical data and number with percentage for categorical data. The Students t-test was used for continuous variables, and the chisquare test was used for categorical variables. A P-value less than 0.05 was considered significant. STATA ver. 12.0 (STATA Corporation, College Station, TX, USA) was used for statistical analysis.

\section{RESULTS}

\section{Baseline characteristics}

A total of 271 questionnaires were distributed, and 255 EMS personnel (94\%) completed the survey by the end of the conference. Of the eligible participants, 126 (49\%) were first-degree EMTs. Baseline characteristics of each group including age, gender, and EMS career duration are described in Table 1. The mean age of the participants was 34 years, and 219 (86\%) participants were men.

\section{Knowledge and perception of sepsis}

Of the 255 participants, 242 (95\%) were aware of the term "sep- 
Table 1. Baseline characteristics

\begin{tabular}{lcccr}
\hline & $\begin{array}{c}\text { Overall } \\
(n=255)\end{array}$ & $\begin{array}{c}\text { First-degree } \\
\text { EMT group } \\
(n=126)\end{array}$ & $\begin{array}{c}\text { Non-first-de- } \\
\text { gree EMT group P-value } \\
(\mathrm{n}=129)\end{array}$ & \\
\hline Age (yr) & $34 \pm 6$ & $31 \pm 5$ & $36 \pm 7$ & $<0.01$ \\
Sex (male, \%) & $219(86)$ & $92(73)$ & $127(98)$ & $<0.01$ \\
EMS career (yr) & $4.3 \pm 4.0$ & $4.8 \pm 4.2$ & $3.9 \pm 3.7$ & 0.07 \\
Training site before EMS & & & & $<0.01$ \\
Teaching hospital & $95(37)$ & $77(61)$ & $18(14)$ & \\
Non-teaching hospital & $32(13)$ & $16(13)$ & $16(12)$ & \\
None & $128(50)$ & $33(26)$ & $95(74)$ & \\
\hline
\end{tabular}

Data are shown as mean \pm standard deviation or number (\%).

EMT, emergency medical technician; EMS, emergency medical service. sis" (01 in Table 2). Only 171 (67\%) participants, however, correctly defined sepsis (02) (75\% in the first-degree EMT group vs. $59 \%$ in the non-first-degree EMT group, $\mathrm{P}<0.01$ ). First-degree EMTs better understood common signs, symptoms, and treatment options for sepsis than did non-first-degree EMTs. In total, 223 $(87 \%)$ participants noted that fever was the most frequent symptom of sepsis, followed by altered mental status (78\%) (03). Relatively few subjects had sufficient knowledge regarding tachycardia $(73 \%)$, tachypnea $(68 \%)$, hypotension $(49 \%)$, and hypothermia (20\%).

Most of the group was aware of the importance of antibiotics

Table 2. Knowledge and perception of sepsis

\begin{tabular}{|c|c|c|c|c|}
\hline & $\begin{array}{c}\text { Overall } \\
(n=255)\end{array}$ & $\begin{array}{l}\text { First-degree } \\
\text { EMT group } \\
(n=126)\end{array}$ & $\begin{array}{l}\text { Non-first-degree } \\
\text { EMT group } \\
(n=129)\end{array}$ & P-value \\
\hline Q1. Have you ever heard of the term "sepsis"? (yes) & $242(95)$ & $123(98)$ & 119 (92) & 0.05 \\
\hline Q2. Definition of sepsis (correct answer) & $171(67)$ & $95(75)$ & $76(59)$ & $<0.01$ \\
\hline \multicolumn{5}{|c|}{ Q3. Do you think the following symptoms and signs are associated with sepsis? } \\
\hline $\begin{array}{l}\text { Fever } \\
\text { Yes } \\
\text { No or not sure }\end{array}$ & $\begin{array}{r}223(87) \\
32(13)\end{array}$ & $\begin{array}{c}121(96) \\
5(4)\end{array}$ & $\begin{array}{r}102(79) \\
27(21)\end{array}$ & $<0.01$ \\
\hline $\begin{array}{l}\text { Hypothermia } \\
\text { Yes } \\
\text { No or not sure }\end{array}$ & $\begin{array}{r}50(20) \\
205(80)\end{array}$ & $\begin{array}{r}22(17) \\
104(83)\end{array}$ & $\begin{array}{r}28(22) \\
101(78)\end{array}$ & 0.39 \\
\hline $\begin{array}{l}\text { Tachycardia } \\
\text { Yes } \\
\text { No or not sure }\end{array}$ & $\begin{array}{r}185(73) \\
70(27)\end{array}$ & $\begin{array}{r}110(87) \\
16(13)\end{array}$ & $\begin{array}{l}75(58) \\
54(42)\end{array}$ & $<0.01$ \\
\hline $\begin{array}{l}\text { Hypotension } \\
\text { Yes } \\
\text { No or not sure }\end{array}$ & $\begin{array}{l}125(49) \\
130(51)\end{array}$ & $\begin{array}{l}76(60) \\
50(40)\end{array}$ & $\begin{array}{l}49(38) \\
80(62)\end{array}$ & $<0.01$ \\
\hline $\begin{array}{l}\text { Altered mental status } \\
\text { Yes } \\
\text { No or not sure }\end{array}$ & $\begin{array}{r}199(78) \\
56(22)\end{array}$ & $\begin{array}{r}111(88) \\
15(12)\end{array}$ & $\begin{array}{l}88(68) \\
41(32)\end{array}$ & $<0.01$ \\
\hline \multicolumn{5}{|c|}{ Q4. Do you think the following treatments are essential for sepsis management? } \\
\hline $\begin{array}{l}\text { Antibiotics } \\
\text { Yes } \\
\text { No or not sure }\end{array}$ & $\begin{array}{r}200(78) \\
55(22)\end{array}$ & $\begin{array}{r}114(90) \\
12(10)\end{array}$ & $\begin{array}{l}86(67) \\
43(33)\end{array}$ & $<0.01$ \\
\hline
\end{tabular}

Data are shown as number (\%).

EMT, emergency medical technician. 
(78\%), while fluid resuscitation (61\%) and vasopressors in shock $(35 \%)$ were less frequently considered as essential therapeutic measures (04). Only 38 (15\%) participants had suspected sepsis in a patient during transportation (26\% and 4\% of participants in the first-degree EMT group and the non-first-degree EMT group, respectively) (05).

Table 3. Attitudes toward sepsis

\begin{tabular}{|c|c|c|c|c|}
\hline & $\begin{array}{c}\text { Overall } \\
(n=255)\end{array}$ & $\begin{array}{l}\text { First-degree } \\
\text { EMT group } \\
(n=126)\end{array}$ & $\begin{array}{l}\text { Non-first-degree } \\
\text { EMT group } \\
(n=129)\end{array}$ & P-value \\
\hline Q6. Do you think EMTs can diagnose sepsis in the prehospital setting? & & & & 0.48 \\
\hline Yes & $23(9)$ & $13(10)$ & $10(8)$ & \\
\hline No or not sure & $232(91)$ & $113(90)$ & $119(92)$ & \\
\hline Q7. Do you think EMTs should be involved in the management of sepsis in the prehospital setting? & & & & 0.10 \\
\hline Yes & $151(59)$ & $81(64)$ & $70(54)$ & \\
\hline No or not sure & $104(41)$ & $45(36)$ & $59(46)$ & \\
\hline $\begin{array}{l}\text { Q8. Do you think medical intervention by EMTs in the prehospital setting will improve outcomes for } \\
\text { sepsis patients? }\end{array}$ & & & & 0.81 \\
\hline Yes & $160(63)$ & $80(63)$ & $80(62)$ & \\
\hline No or not sure & $95(37)$ & $46(37)$ & $49(38)$ & \\
\hline $\begin{array}{l}\text { 09. Do you think medical intervention by EMTs in the prehospital setting will positively influence } \\
\text { the behavior of the medical team in the emergency department? }\end{array}$ & & & & 0.51 \\
\hline Yes & $149(58)$ & $71(56)$ & $78(60)$ & \\
\hline No or not sure & $106(42)$ & $55(44)$ & $51(40)$ & \\
\hline Q10. Are you willing to actively engage in the management of sepsis in the prehospital setting? & & & & $<0.01$ \\
\hline Yes & $154(60)$ & $95(75)$ & $59(46)$ & \\
\hline No or not sure & $101(40)$ & $31(25)$ & $70(54)$ & \\
\hline
\end{tabular}

Data are shown as number (\%).

EMT, emergency medical technician.

Table 4. Comparison of knowledge and attitudes according to activeness of emergency medical service personnel

\begin{tabular}{|c|c|c|c|c|c|c|}
\hline & \multicolumn{3}{|c|}{ Overall } & \multicolumn{3}{|c|}{ First-degree EMT } \\
\hline & $\begin{array}{c}\text { Active } \\
\text { group } \\
(n=154)\end{array}$ & $\begin{array}{c}\text { Passive } \\
\text { group } \\
(n=101)\end{array}$ & P-value & $\begin{array}{c}\text { Active } \\
\text { group } \\
(n=95)\end{array}$ & $\begin{array}{c}\text { Passive } \\
\text { group } \\
(n=31)\end{array}$ & P-value \\
\hline Q2. Definition of sepsis (correct answer) & $104(68)$ & $67(66)$ & 0.84 & $72(76)$ & $23(74)$ & 0.86 \\
\hline \multicolumn{7}{|l|}{ Q3. Do you think the following symptoms and signs are associated with sepsis? } \\
\hline Fever & $137(89)$ & $86(85)$ & 0.37 & $92(97)$ & $29(94)$ & 0.42 \\
\hline Hypothermia & $31(20)$ & $19(19)$ & 0.80 & $18(19)$ & $4(13)$ & 0.44 \\
\hline Tachycardia & $125(81)$ & $60(59)$ & $<0.01$ & $86(91)$ & $24(77)$ & 0.06 \\
\hline Tachypnea & $116(75)$ & $58(57)$ & $<0.01$ & 79 (83) & $23(74)$ & 0.27 \\
\hline Hypotension & $88(57)$ & $37(37)$ & $<0.01$ & $58(61)$ & $18(58)$ & 0.77 \\
\hline Altered mental status & $122(79)$ & $77(76)$ & 0.57 & $82(87)$ & $28(90)$ & 0.66 \\
\hline \multicolumn{7}{|l|}{ Q4. Do you think the following treatments are essential for sepsis management? } \\
\hline Antibiotics & $128(83)$ & $72(71)$ & 0.03 & $86(91)$ & $28(90)$ & 0.97 \\
\hline Fluid resuscitation & $106(69)$ & $50(50)$ & $<0.01$ & 73 (77) & $24(77)$ & 0.95 \\
\hline Vasopressors in shock & $63(41)$ & $26(26)$ & 0.01 & $43(45)$ & $12(39)$ & 0.52 \\
\hline $\begin{array}{l}\text { 05. Have you ever suspected that a patient was suffering from sepsis during } \\
\text { transport to the hospital? }\end{array}$ & $34(22)$ & $4(4)$ & $<0.01$ & 31 (33) & $2(6)$ & $<0.01$ \\
\hline Q6. Do you think EMTs can diagnose sepsis in the prehospital setting? & $18(12)$ & $5(5)$ & 0.07 & $12(13)$ & $1(3)$ & 0.14 \\
\hline $\begin{array}{l}\text { Q7. Do you think EMTs should be involved in the management of sepsis in the } \\
\text { prehospital setting? }\end{array}$ & $109(71)$ & $42(42)$ & $<0.01$ & $65(68)$ & $16(52)$ & 0.09 \\
\hline $\begin{array}{l}\text { Q8. Do you think medical intervention by EMTs in the prehospital setting will } \\
\text { improve outcomes for sepsis patients? }\end{array}$ & $116(75)$ & $44(44)$ & $<0.01$ & 66 (69) & $14(45)$ & 0.02 \\
\hline $\begin{array}{l}\text { 09. Do you think medical intervention by EMTs in the prehospital setting will } \\
\text { influence the behavior of the medical team in the emergency department? }\end{array}$ & 111 (72) & $38(38)$ & $<0.01$ & $61(64)$ & $10(32)$ & $<0.01$ \\
\hline
\end{tabular}

Data are shown as number (\%) answered "yes" to each question except "definition of sepsis".

EMT, emergency medical technician. 


\section{Attitude toward prehospital sepsis care}

Only $9 \%$ of subjects reported that they could identify patients with sepsis during transportation (06 in Table 3). More than half of the participants (59\%) agreed that EMS personnel should be involved in prehospital sepsis care (07). Sixty-three percent responded that their intervention would improve the outcome of patients with sepsis (08), and 58\% responded that their intervention would positively influence the behavior of the medical team in the ED (09).

Of the participants, $154(60 \%)$ were actively willing to be involved in prehospital sepsis care, while 101 (40\%) subjects responded in a passive manner (010). There was a significant difference between the first-degree EMT group and the non-first-degree EMT group with regard to willingness to be involved in prehospital sepsis care $(75 \%$ vs. $46 \%, \mathrm{P}<0.01)$.

\section{The active group vs. the passive group}

Overall, the active group had better knowledge of sepsis than the passive group, and the differences were statistically significant in responses to 03 ( $81 \%$ vs. 59\% for tachycardia, $75 \%$ vs. $57 \%$ for tachypnea, and $57 \%$ vs. $37 \%$ for hypotension) and 04 (83\% vs. $71 \%$ for antibiotics, $69 \%$ vs. $50 \%$ for fluid resuscitation, and $41 \%$ vs. $26 \%$ for vasopressors in shock) (Table 4). The proportion who had ever suspected sepsis in a patient during transportation was significantly higher in the active group ( $22 \%$ vs. $4 \%$ overall and $33 \%$ vs. $6 \%$ in the first-degree EMT group) (05). The active group showed a significantly more positive attitude towards prehospital sepsis care, as seen in 07 (71\% vs. 42\%), 08 (75\% vs. 44\%), and 09 (72\% vs. 38\%). The trends between the active and the passive groups were less prominent in the first-degree EMT group.

\section{DISCUSSION}

The EMS system has contributed to an improvement in the outcomes of several time-critical diseases in the prehospital setting, such as acute myocardial infarction and cardiac arrest. ${ }^{15,16}$ Sepsis is similar and requires immediate intervention. ${ }^{17}$ Previous studies have shown that a significant proportion of patients with sepsis were transported by the EMS system. ${ }^{7-10}$ Therefore, EMS personnel have crucial roles in early identification of sepsis, timely initiation of elements of treatment, and transporting patients to the appropriate hospital.

We found a lack of knowledge and perception of sepsis among EMS personnel in Korea, in terms of definition, clinical signs, symptoms, and treatment options. EMS personnel who expressed their intention to actively participate in prehospital sepsis care had a better understanding of sepsis and a more positive attitude to- ward prehospital care for sepsis patients. However, the $40 \%$ of EMS personnel who were only passively willing to be involved in sepsis care had lower levels of knowledge and awareness for sepsis. They also had negative impressions of the clinical roles of EMS in sepsis care. These findings suggest a need for improved understanding of sepsis and encouraged involvement by providing education about sepsis and current evidence about prehospital sepsis care.

Our study suggested that lack of knowledge was not the only barrier to care; some subjects had difficulty implementing their knowledge, considering that very few EMTs had ever suspected their patients were suffering from sepsis. Recognizing sepsis is a key step to initiating appropriate care, but it is very challenging in the prehospital setting due to limited clinical information. ${ }^{18}$ For EMS personnel, a feasible prehospital protocol to enhance early diagnosis and management is needed. For example, use of systematic screening tools and an on-scene point-of care lactate test might help EMS personnel to identify severe sepsis in the prehospital setting.

Early recognition of sepsis by prehospital personnel should lead to transport of patients to the proper hospital and behavioral changes in hospital staff. ${ }^{19}$ More than half of the EMS personnel (58\%) agreed that their medical intervention would positively influence the behavior of in-hospital staff. This tendency was remarkably stronger in the active group compared to the passive group. Studnek et al. ${ }^{7}$ confirmed that ED arrival by EMS triggered the in-hospital cascade of sepsis care, resulting in a shorter time to initiation of antibiotics and early goal-directed therapy in patients with severe sepsis.

Prehospital sepsis care has not been a subject of intense interest for several decades. Although Seymour et al..$^{11}$ showed that prehospital fluid administration and placement of intravenous access decreased hospital mortality compared to no intervention, the importance of prehospital sepsis care and the ability of EMS personnel to improve sepsis outcomes are unknown. Further research is needed to establish clear roles of EMS personnel in sepsis care before hospital arrival.

This study has several limitations. First, the study was carried out during educational conferences for EMS personnel working in a metropolitan city. Therefore, our findings might not be generalizable to other settings such as the rural EMS system. Second, the participant number was relatively small, although the number of first-degree EMTs in this study was approximately $25 \%$ of all firstdegree EMTs working at Seoul Metropolitan Fire \& Disaster Headquarters at the time of the survey. ${ }^{13}$ Third, these participants had relatively short EMS career durations compared to participants in previous studies, ${ }^{14}$ which could have influenced the results. 
In conclusion, appropriate knowledge and perceptions regarding sepsis care were insufficient among EMS personnel in Korea. EMS personnel who were actively willing to be involved in sepsis care before hospital arrival showed better knowledge and perception of sepsis compared to those who did not. To reinforce the survival chain of sepsis from the prehospital setting, targeted education for EMS personnel and systematic implementation of a feasible protocol to enhance early management of sepsis will be needed.

\section{CONFLICT OF INTEREST}

No potential conflict of interest relevant to this article was reported.

\section{REFERENCES}

1. Martin GS, Mannino DM, Eaton S, Moss M. The epidemiology of sepsis in the United States from 1979 through 2000. N Engl J Med 2003;348:1546-54.

2. Taniguchi LU, Bierrenbach AL, Toscano CM, Schettino GP, Azevedo LC. Sepsis-related deaths in Brazil: an analysis of the national mortality registry from 2002 to 2010. Crit Care 2014; 18:608.

3. Rivers E, Nguyen B, Havstad S, et al. Early goal-directed therapy in the treatment of severe sepsis and septic shock. N Engl J Med 2001;345:1368-77.

4. Gaieski DF, Mikkelsen ME, Band RA, et al. Impact of time to antibiotics on survival in patients with severe sepsis or septic shock in whom early goal-directed therapy was initiated in the emergency department. Crit Care Med 2010;38:1045-53.

5. Joo YM, Chae MK, Hwang SY, et al. Impact of timely antibiotic administration on outcomes in patients with severe sepsis and septic shock in the emergency department. Clin Exp Emerg Med 2014;1:35-40.

6. Vincent JL, Pereira AJ, Gleeson J, Backer DD. Early management of sepsis. Clin Exp Emerg Med 2014;1:3-7.

7. Studnek JR, Artho MR, Garner CL Jr, Jones AE. The impact of emergency medical services on the ED care of severe sepsis. Am J Emerg Med 2012;30:51-6.

8. Wang HE, Weaver MD, Shapiro NI, Yealy DM. Opportunities for Emergency Medical Services care of sepsis. Resuscitation 2010;81:193-7.
9. van der Wekken LC, Alam N, Holleman F, van Exter P, Kramer $\mathrm{MH}$, Nanayakkara PW. Epidemiology of sepsis and its recognition by emergency medical services personnel in the netherlands. Prehosp Emerg Care 2016;20:90-6.

10. Seymour CW, Rea TD, Kahn JM, Walkey AJ, Yealy DM, Angus DC. Severe sepsis in pre-hospital emergency care: analysis of incidence, care, and outcome. Am J Respir Crit Care Med 2012; 186:1264-71.

11. Seymour CW, Cooke CR, Heckbert SR, et al. Prehospital intravenous access and fluid resuscitation in severe sepsis: an observational cohort study. Crit Care 2014;18:533.

12. Shime N. A survey of the competency of ambulance service personnel in the diagnosis and management of sepsis. J Emerg Med 2015;49:147-51.

13. Seoul Metropolitan Fire \& Disaster Headquarters. Organization [Internet]. Seoul: Seoul Metropolitan Fire \& Disaster Headquarters [cited 2016 Jul 19]. Available from: http://fire.seoul. go.kr/english/pages/cnts.do?id = 1701 .

14. Seymour CW, Carlbom D, Engelberg RA, et al. Understanding of sepsis among emergency medical services: a survey study. J Emerg Med 2012;42:666-77.

15. Mathews R, Peterson ED, Li S, et al. Use of emergency medical service transport among patients with ST-segment-elevation myocardial infarction: findings from the National Cardiovascular Data Registry Acute Coronary Treatment Intervention Outcomes Network Registry-Get with the Guidelines. Circulation 2011;124:154-63.

16. Hollenberg J, Herlitz J, Lindqvist J, et al. Improved survival after out-of-hospital cardiac arrest is associated with an increase in proportion of emergency crew: witnessed cases and bystander cardiopulmonary resuscitation. Circulation 2008; 118:389-96.

17. Dellinger RP, Levy MM, Rhodes A, et al. Surviving sepsis campaign: international guidelines for management of severe sepsis and septic shock: 2012. Crit Care Med 2013;41:580-637.

18. Suffoletto B, Frisch A, Prabhu A, Kristan J, Guyette FX, Callaway $C W$. Prediction of serious infection during prehospital emergency care. Prehosp Emerg Care 2011;15:325-30.

19. Band RA, Gaieski DF, Hylton JH, Shofer FS, Goyal M, Meisel ZF. Arriving by emergency medical services improves time to treatment endpoints for patients with severe sepsis or septic shock. Acad Emerg Med 2011;18:934-40. 


\section{Appendix 1. Questionnaire}

Baseline characteristics

1. Age ( )

2. Gender

A. Male

B. Female

3. Emergency medical service (EMS) career duration

4. Emergency medical technician (EMT) grade

A. First-degree EMT

B. Non-first-degree EMT

5. Training site before working in EMS

A. Teaching hospital

B. Non-teaching hospital

C. Not trained

Questions

1. Have you ever heard of the term "sepsis"?

A. Yes

B. No

2. Which one do you think is the most appropriate definition of sepsis?

A. Blood contamination by dirty materials

B. Life-threatening food poisoning after ingestion of seafood such as fish and shellfish

C. Life-threatening infectious disease caused by multidrug-resistant bacteria

D. Systemic inflammatory response caused by microbial infection

E. Allergic reaction against microbes

3. Do you think the following symptoms and signs are associated with sepsis?

A. Fever

i. Yes

ii. No or not sure

B. Hypothermia

i. Yes

ii. No or not sure

C. Tachycardia

i. Yes

ii. No or not sure

D. Tachypnea

i. Yes

ii. No or not sure

E. Hypotension

i. Yes

ii. No or not sure

F. Altered mental status

i. Yes

ii. No or not sure 
Joongmin Park, et al.

4. Do you think the following treatments are essential for sepsis management?

A. Antibiotics

i. Yes

ii. No or not sure

B. Fluid resuscitation

i. Yes

ii. No or not sure

C. Vasopressors in shock

i. Yes

ii. No or not sure

5. Have you ever suspected that a patient was suffering from sepsis during transport to the hospital?

A. Yes

B. No or not sure

6. Do you think emergency medical technicians can diagnose sepsis in the prehospital setting?

A. Yes

B. No or not sure

7. Do you think EMTs should be involved in the management of sepsis in the prehospital setting?

A. Yes

B. No or not sure

8. Do you think medical intervention by EMTs in the prehospital setting will improve outcomes for sepsis patients?

A. Yes

B. No or not sure

9. Do you think medical intervention by EMTs in the prehospital setting will influence the behavior of the medical team in the emergency department?

A. Yes

B. No or not sure

10. Are you willing to be actively engaged in the management of sepsis in the prehospital setting?

A. Yes

B. No or not sure 